\section{Amelia Gamoneda y Francisco GonZÁLEZ, eds., Idea súbita. Ensayos sobre epifanía creativa.}

Madrid, Abada, 20I8, 267 pp.

Recibido: 01/04/2019

Aceptado: 24/04/2019

El ser humano, siempre en busca de respuestas a los interrogantes que manan de su existencia, se topa con la dificultad de definir y demostrar empíricamente el fenómeno por el cual encuentra las respuestas a esas preguntas, el momento de epifanía, de aparición súbita de una idea. ¿Cómo ocurre este fenómeno? Frecuentemente tendemos a pensar el discurrir de la conciencia como un movimiento temporal, pero ies posible teorizar sobre un instante que forma parte de este discurrir, teniendo en cuenta los propios problemas que ofrece la conceptualización del tiempo? ¿Es posible describir cómo el cerebro crea, clasifica y expande un mundo desde sí mismo? ¿Podemos dar con la génesis de su propia actividad? A la luz de estas y otras posibles preguntas, la propuesta teórica de Idea súbita: ensayos sobre epifanía creativa parece tener una perspectiva ecuménica. Este tomo, coordinado por Amelia Gamoneda y Francisco González y editado por Abada, contiene diez ensayos que arrojan luz - y creatividad propia- a un terreno farragoso en el que interseccionan disciplinas como la epistemología, las matemáticas, la neurociencia, las ciencias cognitivas, teorías de la estética del arte, literatura, lingüística y semiótica. Además, constituye la tercera de una serie de publicaciones dirigidas por Amelia Gamoneda y dedicadas a la exploración de la frontera entre ciencias y arte, específicamente, entre ciencias cognitivas y literatura. Así son Metáfora y ciencia: cuando dos y dos no son cuatro, publicado por Revista de Occidente (2015) y Espectro de la analogía: literatura y ciencia, por Abada (20I6). Una lectura previa de estas publicaciones resulta especialmente recomendada con respecto a las implicaciones

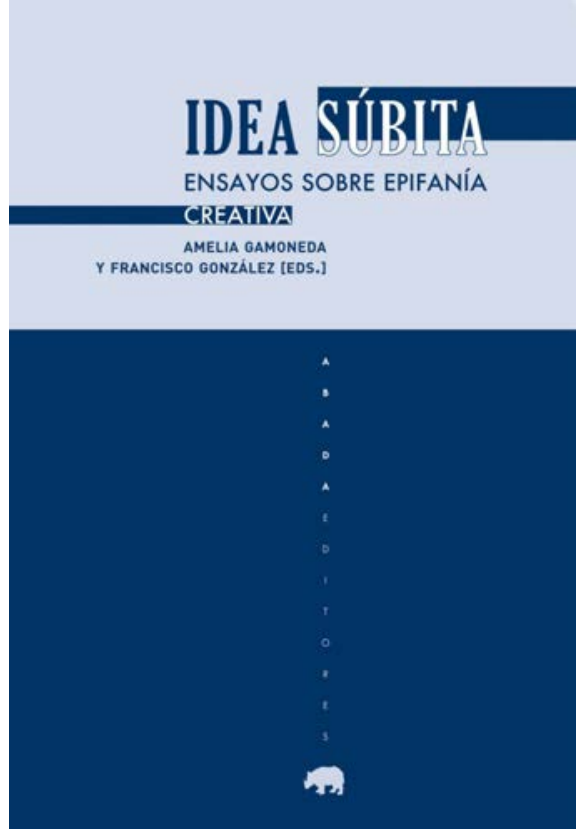

de los fenómenos como la metáfora y la analogía, claves para abordar el fenómeno epifánico en Idea súbita.

Los diversos abordajes del tema contenidos en la obra ofrecen una panorámica enriquecedora y en ocasiones sorprendente. Mientras que la mayoría de los capítulos inciden recurrentemente en la investigación científica y la creación literaria, el lector atento no tardará en generar sus propios eurekas al encontrar puntos de contacto (analogías) con otras disciplinas en las que haya experimentado cierta "euforia" ante un hallazgo o durante un momento de creatividad. Esta emoción es la misma de la que hablaban los poetas del Romanticismo cuando se sentían poseídos por la musa, explicación que Platón trató de dar ante un fenómeno de difícil explicación en aquella época. Así pues, lo que probablemente mantenga al investigador o creador a la zaga de su tortuoso trabajo es el adictivo mecanismo de recompensa que se produce al hallazgo de una novedad. Este brote de alegría parece también subyacer a otros contextos: desde las novelas de enigma y policíacas hasta los mecanismos de tensión y resolución en la música, piedra 
angular de la improvisación de jazz. Es este mecanismo el motor del hallazgo, como apunta Germán Sierra en Un ensordecedor crepitar de eurekas. Teniendo en cuenta los engranajes de emotividad que se activan en tal instante, no sorprende que tradicionalmente la literatura y la religión le atribuyeran cierta cualidad mística, denominándolo epifanía o iluminación. De la distinción terminológica del hallazgo se ocupa el artículo de Gamoneda, Eureka y epifanía. Diluciones cognitivas y poéticas. Sin embargo, el proceso previo a este punto es el mismo: un trabajo subliminal del cerebro, estimulado por las horas de estudio, de absorción de información y rompecabezas.

Más difícil de clarificar parece el concepto de subconsciente, que aparece en los respectivos capítulos de Dahan Gaida y Javier Moreno (El efecto "eureka" en la ciencia y la literatura y La metáfora como acontecimiento). Ambos apuntan a que el momento eureka parece producirse en el paso de la idea al consciente que ha ido gestándose en el subconsciente. Arthur Koestler, a propósito de esto, apuntó que parece estar a medio camino entre el sueño y la vigilia. Sin embargo, hay un proceso previo que Poincaré ya trató de definir en 1908, planteando un modelo de cuatro fases constitutivas del proceso creativo. A pesar de la relativa oscuridad en la que nos encontramos con respecto a la comprensión de lo subconsciente, no resultaría tan extraño plantear la posibilidad de la existencia de un trabajo mental que sucede en segundo plano, del mismo modo que la circulación, la digestión y otros muchos procesos biológicos se producen de manera autónoma sin que nuestra voluntad o conciencia medie en ellos. Este trabajo subliminal podría ser comparable a una especie de "inteligencia" ya "programada" -sin que esto nos remita a términos similares usados desde la pseudociencia-, que nos mantendría vivos y que, por qué no, generaría también las posibles soluciones a interrogantes que hemos estado tratando de encontrar de manera infructuosa a través de mecanismos conscientes. Esta "programación" nos lleva también a hablar de la intuición que, para Poincaré, es "el verdadero instrumento de la invención”, según explica Dahan-Gaida.
La relación entre lo verdadero y lo bello (es decir, la dimensión estética) es el criterio de veracidad en las matemáticas. A propósito, Francisco González Fernández explica en El universo en una taza de té que Poincaré creía que estas "no pueden alcanzar las cosas, sino únicamente las relaciones entre cosas". Sin embargo, el crítico aprovecha las teorías de Poincaré para reflexionar acerca del poder de la evocación y la filosofía oriental, por medio del más que conocido pasaje del té y la magdalena de En busca del tiempo perdido de Proust. Pedro Serra, por su parte, en Aesthesis de la subitaneidad moderna: Bohrer y la elusión de la referencia metafísica, realiza una reflexión de lo súbito desde una perspectiva estética. La "subitaneidad", en este caso, se referiría a lo instantáneo, como las "epifanías" de la literatura de James Joyce o los "momentos del ser" de Virginia Woolf. Literatura que "media un súbito contacto sensible con el mundo", concomitante a la función relacional de las matemáticas de Poincaré. Desde luego, parece tratarse de dos lenguajes con ciertas similitudes. Javier Moreno, en su artículo La metáfora como acontecimiento, también ofrece una visión del fenómeno desde la matemática. La teoría de conjuntos le sirve de herramienta para explorar el concepto central de analogía. También explica lo que diferencia la analogía de la metáfora, para abogando finalmente por una visión de esta última como "un acontecimiento histórico", no un "suceso ontológico".

Sin embargo, si hay algo que caracteriza al hallazgo, no es solo la inmediatez de su llegada, súbita, sino su modo, "por accidente", de forma inesperada: la serendipia. Este término, que ha ido cobrando reciente popularidad en la lengua española, ya existía en el inglés desde que el londinense Horace Walpole lo acuñara en el siglo XVII. Sylvie Catellin dedica su artículo La serendipia, motor del descubrimiento a la exploración de este concepto. Al plantearse cuál es la causa del descubrimiento, a menudo se suele apuntar al azar, siendo en realidad esta una elección terminológica que encubre u oscurece el verdadero proceso de serendipia. Ligado a ella está el concepto de abducción, introducido por Pierce y vinculado también con la emergencia -lo que emerge. Es el 
proceso dialéctico contrario a la deducción: un "flash" o una "fuerza inconsciente" que da lugar a la hipótesis. Mirko Lampis, en su capítulo sobre Creatividad, cultura y lógica abductiva, aporta una mirada semiótica del acto creativo y no tanto del proceso mental previo, postulando cómo la razón abductiva actúa seleccionando "las hipótesis que mejor explican las conclusiones y casos conocidos". Semiótica es traducción (recordemos a Eco), y en este sentido, la inspiración supone un paso de "la intraductibilidad a la traductibilidad".

Por último, Carlos López de Silanes intenta abordar el concepto de mente en su relación con respecto a lo corporal y al mundo en Negro sobre blanco. Intuición y epifanía en los signos. El conocimiento de la realidad, que nos llega "de manera empírica, de abajo a arriba”, se plasma en nuestro sistema inmune "tras exponerse a la infinidad de antígenos" que se han dado en el ser humano y se sistematiza en el lenguaje, lo que, a su juicio, indica un origen filogenético del mismo. El lenguaje es conocimiento, por tanto, y un reflejo de esa "materia oscura" que es la realidad y el pensamiento.

No podemos hablar de la cognición humana sin referirnos en algún momento a la realidad aprehensible y a las disciplinas más elementales que tratan de explicarla. Así pues, es el carácter interdisciplinar -en opinión de Sylvie Catellinlo fundamental para que la serendipia haga avanzar el estudio de la cognición humana, del mismo modo que lo es la crítica del propio conocimiento (epistemocrítica). Idea súbita podría presentarse como una lectura algo compleja para aquellos no familiarizados con la variedad de su abanico conceptual y relacional. Esto, lejos de ser una advertencia, representa una viva invitación al lector a dejarse ser inspirado e indagar en un campo de estudio prometedor que va cobrando más y más importancia en el avance de las Humanidades.

Laura Isabel García Sánchez Universidad de Salamanca misirlau@gmail.com

ORCID iD: https://orcid.org/0000-0003-0646-866X 